CLINICAL STUDY

\title{
Overweight is associated with impaired $\beta$-cell function during pregnancy: a longitudinal study of 553 normal pregnancies
}

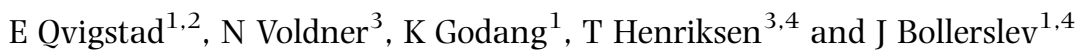 \\ ${ }^{1}$ Department of Endocrinology, Rikshospitalet, Oslo University Hospital, Oslo 0027, Norway, ${ }^{2}$ Division of Obstetrics and Gynecology, Norwegian \\ Resource Centre of Women's Health, Oslo 0027, Norway, ${ }^{3}$ Department of Obstetrics and Gynecology, Rikshospitalet, Oslo University Hospital, \\ Oslo 0027, Norway and ${ }^{4}$ Faculty of Medicine, University of Oslo, Oslo 0027, Norway \\ (Correspondence should be addressed to E Qvigstad at Department of Endocrinology, Rikshospitalet, Oslo University Hospital; \\ Email: elisabeth.qvigstad@rikshospitalet.no)
}

\begin{abstract}
Objective: To monitor $\beta$-cell function and insulin sensitivity longitudinally in a large cohort of pregnant women to elucidate mechanisms that influence glycemic control in pregnancy.

Design and methods: Five hundred and fifty-three pregnant Scandinavian women underwent $75 \mathrm{~g}$ oral glucose tolerance test (OGTT) at weeks 14-16 and 30-32. Insulin sensitivity (Matsuda index) and $\beta$-cell function (ratio of $\mathrm{AUC}_{\text {insulin }}$ to $\mathrm{AUC}_{\text {glucose }}, \mathrm{AUC}_{\text {ins/glc }}$ ) were calculated from 520 complete tests, and subsequently $\beta$-cell function was adjusted for insulin sensitivity, rendering an oral disposition index $\left(\mathrm{DI}_{\mathrm{o}}\right)$.

Results: Eleven women (2.1\%) had gestational diabetes mellitus (GDM1) at weeks 14-16, and 49 $(9.4 \%)$ at weeks 30-32 (GDM2), which is higher than that previously reported in this region. In the subdivision of OGTT, more overweight (body mass index $>25$ ) was found in glucose-intolerant groups (glucose-tolerant women (normal glucose tolerance, NGT) 38 versus GDM2 women 58 and GDM1 women $82 \%, P<0.005)$. In early pregnancy, insulin sensitivity was lowest in GDM1, intermediate in GDM2, and highest in NGT. In late pregnancy, insulin sensitivity decreased in all groups, most in gestational diabetes. $\beta$-cell function demonstrated minor shifts during pregnancy, but when adjusted for decreasing insulin sensitivity, $\mathrm{DI}_{\mathrm{o}}$ levels fell by $40 \%(P<0.001)$. $\mathrm{DI}_{\mathrm{o}}$ was significantly attenuated relative to glucose intolerance (GDM1 25\% and GDM2 53\%) during pregnancy. In overweight women, $\mathrm{DI}_{\mathrm{o}}$ levels were lower throughout pregnancy $(P<0.001$ versus normal weight women), this reduction was significant $(P<0.01)$ in both NGT $(21-25 \%)$ and GDM2 subjects $(26-49 \%)$.

Conclusion: $\beta$-cell function adjusted for insulin sensitivity $\left(\mathrm{DI}_{\mathrm{o}}\right)$ deteriorated during pregnancy in both glucose-tolerant and glucose-intolerant women. The failure to compensate the decrease in insulin sensitivity was accentuated in overweight women.
\end{abstract}

European Journal of Endocrinology 162 67-73

\section{Introduction}

During gestation, there is a gradual decrease in insulin sensitivity (1). A variety of endocrine factors including estrogens, progesterone, human placental lactogen, cortisol, and tumor necrosis factor- $\alpha$ seem to impair the effect of insulin $(2,3)$.

In most pregnant women, some increase in postprandial glucose levels is seen, and in some, mild increases in fasting plasma glucose (FPG) levels are also seen (4). In normal circumstances, euglycemia is maintained during pregnancy due to compensatory hyperinsulinemia. The inverse relationship between the acute insulin response and insulin sensitivity during i.v. glucose tolerance tests is known as the disposition index (DI), and is constant for an individual at a given glucose tolerance level $(5,6)$.

The increasing prevalence of obesity in fertile age (7) contributes to lower insulin sensitivity, and could stress $\beta$-cell function during pregnancy resulting in an increased risk of gestational diabetes mellitus (GDM). Gestational diabetes identifies women at high risk of developing type 2 diabetes, and can provide a model of early events in the development of the disease (8). The physiological increase in insulin resistance (IR) in pregnancy can unmask a previously unknown $\beta$-cell defect in some individuals (9). Women with GDM have been reported to have lower DI during and after pregnancy compared to normoglycemic individuals (9). In addition, GDM is associated with increased risk of maternal and fetal morbidity and with complications on short- and long-term perspective $(10,11)$. Milder dysglycemia (nonGDM) results in intermediate rate of complications, indicating no threshold between the level of glycemia and adverse pregnancy outcome (12).

For assessment of insulin sensitivity, the euglycemic clamp is the reference method (13). However, in larger studies, simplified tests are used such as the oral glucose tolerance test (OGTT). In recent years, a number of 
indices of insulin sensitivity and $\beta$-cell function based on OGTT data have been developed (reviewed in (14)). Validation of such insulin sensitivity indices with clamp studies in pregnancy has been performed (15), and to our knowledge, similar evaluations for $\beta$-cell function in pregnancy have not been reported.

There are few prospective studies of $\beta$-cell function compared to studies of insulin sensitivity in pregnancy. Decreases in $\beta$-cell function are to some degree masked by decreasing insulin sensitivity during pregnancy (16). The DI was developed to adjust for compensatory high insulin responses to a decreased insulin sensitivity based on data obtained from i.v. glucose tolerance tests (6). Recently, the hyperbolic relationship of $\beta$-cell function and insulin sensitivity has also been demonstrated with data obtained from OGTT results in nonpregnant individuals $(17,18)$, and this relationship has not been tested in pregnancy. In pregnant women in late gestation (weeks 24-28), $\beta$-cell function adjusted for insulin sensitivity deteriorated markedly when impaired glucose tolerance (IGT) and GDM individuals were compared with normal glucose tolerance (NGT) individuals, and most so in GDM (19). A recent prospective study in pregnant women of normal weight found falling insulin sensitivity and failing $\beta$-cell function in overt GDM (4). It also plotted the change during pregnancy in $\beta$-cell function (ratio of $\mathrm{AUC}_{\text {insulin }}$ to $\left.\mathrm{AUC}_{\text {glucose }}, \mathrm{AUC}_{\mathrm{ins} / \mathrm{glc}}\right)$ against insulin sensitivity, and could demonstrate a significant defect in compensation for IR in subjects with early onset of GDM, while late-onset GDM subjects did not differ in adjusted $\beta$-cell function when compared to NGT subjects.

The STORK study investigated healthy pregnant Scandinavian women prospectively to evaluate the effects of metabolic markers and anthropometry on pregnancy outcome.

Previous analyses in this cohort indicate that subgroups of overweight women have dissimilar risks of delivering macrosomic newborns depending on the change in fasting glucose throughout pregnancy (20). Normal pregnant women in the upper body mass index (BMI) quartile (BMI above $27 \mathrm{~kg} / \mathrm{m}^{2}$ ) with the highest increase in FPG from early to late pregnancy had a 4.5fold increased risk of delivering a macrosomic infant irrespective of insulin levels. There were no effects of gestational weight gain or macronutrient intake on the risk of macrosomia, nor was there a significant interaction between physical inactivity and BMI (21). The absence of effect on macrosomia of insulin and homeostasis model for assessment of insulin resistance (HOMA-IR) was contrasted by a robust effect of fasting glucose which could indicate that IR is not a major mechanism behind the association between dysglycemia and newborn macrosomia (20). Thus, significant increases in FPG in a subgroup of overweight women with large newborns could possibly result from a subtle $\beta$-cell dysfunction during pregnancy.

The aim of the current study was therefore to evaluate $\beta$-cell function and insulin sensitivity prospectively in a longitudinal cohort of pregnant women with a view of elucidating possible differences between early and late pregnancies in the overall metabolic state using surrogate dynamic indices derived from the OGTT. Furthermore, we wished to explore the impact of adjusting $\beta$-cell function estimates for the decreases in insulin sensitivity seen in pregnancy in this cohort.

\section{Materials and methods}

This prospective study was based on a cohort of 553 women (Table 1) described in detail elsewhere (21). Women with Scandinavian heritage were invited to participate. Exclusion criteria were multiple pregnancies, known diabetes, fetal malformation, or other severe maternal illnesses.

The women came for four antenatal visits during pregnancy. At gestational weeks 14-16 and 30-32, $75 \mathrm{~g}$ OGTTs were performed. In addition, at weeks 22-24 and 36-38 anthropometry was done. Five hundred and twenty participants had OGTT results permitting categorization into glucose tolerance groups. Thirtythree participants had incomplete OGTT data due to preterm birth, hospitalization, difficult venous access, or nausea during the first OGTT. The participants were stratified as glucose tolerant (NGT) or GDM according to the 2-h OGTT results $(<7.8 \mathrm{mmol} / \mathrm{l}(22))$. Subjects with 2-h glucose levels $>7.8 \mathrm{mmol} / \mathrm{l}$ received dietary and lifestyle advice, and none of the GDM subjects required anti-diabetic medication during the study.

\section{Independent variables}

Glucose was measured immediately in EDTA blood by Accu-Chek glucose test strips and glucometer (Roche Diagnostics). Samples were collected in $7 \mathrm{ml}$ Vaccutainer tubes, and centrifuged without delay at room temperature at $3000 \boldsymbol{g}$ for $10 \mathrm{~min}$. Serum was aliquoted immediately and stored at $-80{ }^{\circ} \mathrm{C}$ until analyzed. Insulin samples were assayed in duplicate (RIA, DPC, Los Angeles, CA, USA), and the intra- and inter-assay coefficient of variation values were 4.9 and $5.4 \%$ respectively. Height was self-reported and weight was measured on a digital scale.

Table 1 Cohort characteristics.

\begin{tabular}{lcc}
\hline $\boldsymbol{n}=\mathbf{5 5 3}$ & Mean \pm s.D. & Range \\
\hline Maternal age (years) & $31.2 \pm 4$ & $19-42$ \\
$\begin{array}{l}\text { Maternal weight } \\
\quad(\mathrm{kg}, \text { weeks 14-16) }\end{array}$ & $70.8 \pm 12.1$ & $44.6-123.1$ \\
BMl (weeks 14-16) & $24.9 \pm 4.1$ & $17.5-44.0$ \\
Weight gain during & $10.6 \pm 3.8$ & $-1.2-29.4$ \\
$\quad$ pregnancy (kg) & & \\
Gestational age at birth (weeks) & $40.0 \pm 1.8$ & $28.4-43.1$ \\
Birth weight (g) & $3619 \pm 570$ & $1275-5420$ \\
\hline
\end{tabular}

${ }^{a}$ Change in weight from early (weeks 14-16) to late (weeks 34-36) visits. 


\section{Outcome variables}

Glucose and insulin levels, fasting or during the OGTT, were used for computation. We calculated AUC by the trapezoidal rule for glucose and insulin during OGGT, and $\beta$-cell function was given by the ratio of $A U C_{\text {insulin }}$ to $\mathrm{AUC}_{\text {glucose }}\left(\mathrm{AUC}_{\mathrm{ins} / \mathrm{glc}}\right)$. The Matsuda index ( $\left.\mathrm{IS}_{\text {ogtt }}\right)$ was given by the formula $(10000 / \sqrt{ }((\mathrm{FPG} \times \mathrm{FPI})$ $\times(\overline{\mathrm{G}} \times \overline{\mathrm{I}})))$, where FPG is fasting plasma glucose, FPI is fasting plasma insulin, and $\overline{\mathrm{G}}$ and $\overline{\mathrm{I}}$ represent the mean of glucose or insulin levels during OGTT, was calculated as an estimate of insulin sensitivity (23).

We found a hyperbolic relationship after plotting the ratio of $\mathrm{AUC}_{\text {insulin }}$ to $\mathrm{AUC}_{\text {glucose }}\left(\mathrm{AUC}_{\mathrm{ins} / \mathrm{glc}}\right)$ against the IS $_{\text {ogtt }}$ index, and subsequently calculated an oral $\left(\mathrm{DI}_{\mathrm{o}}=\mathrm{AUC} \mathrm{C}_{\mathrm{ins} / \mathrm{glc}} \times \mathrm{IS}_{\mathrm{ogtt}}\right)$ to adjust $\beta$-cell function for the effect of decreasing insulin sensitivity (17).

\section{Statistical methods}

FPG values had a normal distribution, and differences and changes were analyzed by paired or independent sample $t$-tests as appropriate. FPI values at all the four visits were skewed. Differences and changes in FPI and indices of $\beta$-cell function, insulin sensitivity, and IR were analyzed by nonparametric tests. Wilcoxon signed-rank test for paired samples was used to analyze change, and Kruskal-Wallis test and Mann-Whitney tests were used to compare groups, with Bonferroni corrections when appropriate. The distribution of overweight $\left(\mathrm{BMI}>25 \mathrm{~kg} / \mathrm{m}^{2}\right)$ relative to glucose tolerance category was tested with the $\chi^{2}$ test. All analyses were done by SPSS version 15.0 (Chicago, IL, USA).

\section{Ethics}

The study was approved by the Regional Ethics Committee and performed according to the Declaration of Helsinki, and written informed consent was obtained from the participants.

\section{Results}

Table 1 shows the cohort characteristics. Only $4 \%$ of the participants were smokers, and 53\% were primipara. Eleven participants $(1.9 \%)$ had early-onset GDM (GDM1) at weeks 14-16 and $49(9.4 \%)$ had GDM at weeks 30-32 (GDM2). None of the GDM cases had elevated fasting glucose $(>6.1 \mathrm{mmol} / \mathrm{l})$.

Mean BMI at gestational weeks 14-16 was $24.9 \mathrm{~kg} / \mathrm{m}^{2}$, and mean change in body weight was $10.6 \mathrm{~kg}$ from weeks $14-16$ to 34-36. However, women with GDM1 had significantly higher BMI than NGT subjects $\left(28.3\right.$ vs $\left.24.1 \mathrm{~kg} / \mathrm{m}^{2}, P<0.05\right)$; only two women with GDM1 had BMI below $25 \mathrm{~kg} / \mathrm{m}^{2}$ at weeks 14-16. A subdivision of OGTT groups by BMI demonstrated a preponderance of overweight
(BMI > 25) in glucose-intolerant states (NGT 38\%, GDM2 58\%, and GDM1 $82 \%$ respectively, $\chi^{2}$ test, $P<0.005)$.

\section{Glucose and insulin levels during OGTT}

Glucose and insulin levels demonstrated an upward shift from early to late pregnancy (Fig. 1) in normal weight women and more so in overweight women. However, serum insulin levels demonstrated great inter-individual variability in both groups.
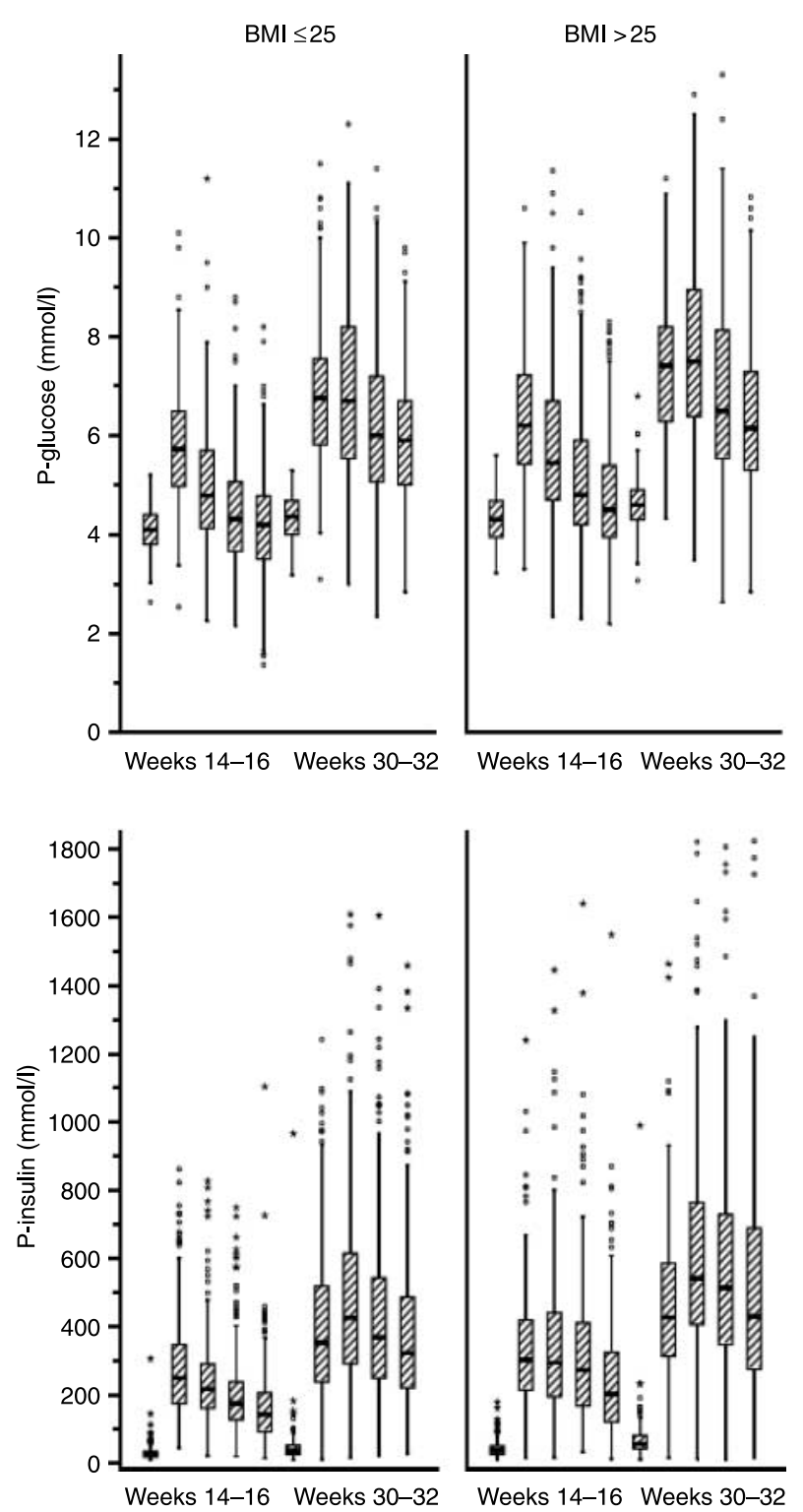

Figure 1 Glucose (upper panels) and insulin (lower panels) levels during OGTT for normal weight $(\mathrm{BMI} \leq 25)$ and overweight women (BMI > 25). Each boxplot cluster depicts tests at weeks 14-16 (left) or 30-32 (right). * or $\bigcirc$ are outliers, some s-insulin extremes are removed. 


\section{Insulin sensitivity indices}

Changes in $I S_{\text {ogtt }}$ from early to late pregnancy Glucose-tolerant women had significant changes in IS $_{\text {ogtt }}$ during pregnancy $(P<0.0001)$. In women with GDM1, IS ogtt tended to decrease $(P<0.08)$. Women with GDM2 demonstrated significant $(P<0.0001)$ reductions in $\mathrm{IS}_{\text {ogtt }}$ (Table 2).

Changes in IS $S_{\text {ogtt }}$ by glucose tolerance categories $\mathrm{IS}_{\text {ogtt }}$ fell during pregnancy in NGT subjects. A greater relative reduction was seen in GDM2 subjects compared to NGT subjects, and the reduction was largest in GDM1 subjects. The difference in insulin sensitivity between GDM1 and GDM2 was most pronounced at weeks 14-16 (30\%, $P<0.01$; Table 2).

Changes in IS ogtt $_{\text {by }}$ BMI categories In individuals with BMI $<25$, an effect of GDM2 was only found at weeks 30-32 when IS $_{\text {ogtt }}$ was $35 \%$ lower $(P<0.002)$ compared to glucose-tolerant individuals (Table 2).

In overweight women with GDM1 and GDM2, IS $_{\text {ogtt }}$ decreased by $\sim 40-60 \%$ in both early and late pregnancies compared to NGT women $(P<0.003)$. IS $_{\text {ogtt }}$ at weeks $14-16$ was $33 \%$ lower $(P<0.04)$ in overweight GDM1 subjects when compared to GDM2 subjects in the same BMI category.

\section{$\beta$-cell function indices $\left(A U C_{\text {ins/glc }}\right)$}

Changes in $A U C_{\text {ins/glc }}$ from early to late pregnancy Glucose-tolerant women had a significant increase in $\mathrm{AUC}_{\text {ins/glc }}$ during pregnancy $(P<0.0001)$, but there was no significant change in GDM1 subjects. GDM2 subjects also demonstrated significant increases in $\beta$-cell function $\left(\mathrm{AUC}_{\mathrm{ins} / \mathrm{glc}}, \mathrm{P}<0.0001\right.$; Table 2$)$.
Changes in $A U C_{i n s / g l c}$ by glucose tolerance categories The levels of $\mathrm{AUC}_{\text {ins/glc }}$ were similar in all glucose tolerance categories in both early and late pregnancies (Table 2). The change in $\mathrm{AUC}_{\mathrm{ins} / \mathrm{glc}}$ levels during pregnancy between the categories was only a trend $(P<0.07)$.

Changes in $\boldsymbol{A U C}_{\text {ins/glc }}$ by BMI categories In overweight women with NGT, $\mathrm{AUC}_{\text {ins/glc }}$ at weeks $14-16$ and 30-32 decreased by 12 and $18 \%$ respectively (both $P<0.0003$, Table 2) compared to NGT women of normal weight.

\section{$\beta$-cell function adjusted for insulin sensitivity level (DIo)}

The changes in $\beta$-cell function during pregnancy relative to insulin sensitivity are shown in Fig. 2. The plots show the expected hyperbolic relationship between estimates of insulin secretion and insulin sensitivity. In both early and late pregnancies, $\mathrm{IS}_{\text {ogtt }}$ was inversely correlated with $\mathrm{AUC}_{\text {ins/glc }}(r=-0.69$ and $r=-0.73$ respectively, both $P<0.0001$ ).

The median $\mathrm{DI}_{\mathrm{o}}$ in early pregnancy was highest in NGT (137), followed by GDM2 (96) and then GDM1 (74), and this shift (Table 3, overall $P<0.0001$ ) supports the idea of a decline in $\beta$-cell function across these groups.

Change in adjusted $\beta$-cell function (DI $)$ from early to late pregnancy The median $\mathrm{DI}_{\mathrm{O}}$ decreased by $28 \%$ from weeks $14-16$ to $30-32 \quad(P<0.0001)$. The reduction of adjusted $\beta$-cell function during pregnancy was $27 \%$ in NGT participants, $P<0.0001$. The impaired $\beta$-cell function was accentuated in the GDM2 group, where $\mathrm{DI}_{\mathrm{o}}$ fell by $35 \%, P<0.0001$. The lowest $\mathrm{DI}_{\mathrm{o}}$ levels were found in GDM1 women, but these levels tended to decline only during pregnancy $(18 \%, P<0.1$; Table 3$)$.

Table 2 Insulin sensitivity and $\beta$-cell function, median ( 25 and 75 th quartiles) by glucose tolerance and body mass index (BMI) categories.

\begin{tabular}{|c|c|c|c|c|}
\hline \multirow[b]{2}{*}{ Gestational weeks } & \multicolumn{2}{|c|}{ Insulin sensitivity $\left(\right.$ IS $\left._{\text {ogtt }}\right)$} & \multicolumn{2}{|c|}{$\beta$-cell function $\left(A \cup C_{\text {ins } / g l c}\right)$} \\
\hline & $14-16$ & $30-32$ & $14-16$ & $30-32$ \\
\hline $\begin{array}{l}\text { NGT }(n=460) \\
\text { GDM1 }(n=11) \\
\text { GDM2 }(n=49)\end{array}$ & $\begin{array}{l}3.32(2.37 ; 4.71) \\
1.45(0.67 ; 1.66)^{\star,}+ \\
2.09(1.46 ; 3.17)^{*}\end{array}$ & $\begin{array}{l}1.66(1.17 ; 2.51) \\
0.84(0.59 ; 1.27)^{\star} \\
1.09(0.80 ; 1.31)^{*}\end{array}$ & $\begin{array}{l}41.3(32.3 ; 55.9) \\
55.7(36.2 ; 99.4) \\
43.3(36.9 ; 55.6)\end{array}$ & $\begin{array}{l}59.3(44.9 ; 79.6) \\
64.9(54.2 ; 90.5) \\
56.1(46.3 ; 70.4)\end{array}$ \\
\hline $\begin{array}{l}\mathrm{BMI} \leq 25 \\
\mathrm{NGT}(n=193) \\
\mathrm{GDM}^{\S} \\
\mathrm{GDM} 2(n=20)\end{array}$ & $\begin{array}{c}3.8(2.8 ; 5.2)^{\ddagger} \\
-\overline{4.2} \\
3.1(2.0 ; 4.2)^{\ddagger}\end{array}$ & $\begin{array}{c}2.0(1.3 ; 2.8)^{\ddagger} \\
- \\
1.3(1.0 ; 2.0)^{\star}, \ddagger\end{array}$ & $\begin{array}{c}39.2(30.4 ; 49.6)^{\ddagger} \\
- \\
42.3(32.4 ; 54.7)\end{array}$ & $\begin{array}{c}54.5(40.9 ; 74.7)^{\ddagger} \\
- \\
55.0(39.4 ; 81.9)\end{array}$ \\
\hline $\begin{array}{l}\mathrm{BMI}>25 \\
\mathrm{NGT}(n=267) \\
\text { GDM1 }(n=9) \\
\text { GDM2 }(n=28)\end{array}$ & $\begin{array}{l}2.6(1.9 ; 3.7) \\
1.2(0.7 ; 1.7)^{\star} \\
1.8(1.3 ; 2.4)^{\star}\end{array}$ & $\begin{array}{l}1.3(1.0 ; 1.8) \\
0.8(0.5 ; 1.2)^{\star} \\
0.9(0.6 ; 1.2)^{\star}\end{array}$ & $\begin{array}{l}47.4(35.3 ; 64.6) \\
75.6(44.6 ; 113.5) \\
45.5(37.5 ; 56.5)\end{array}$ & $\begin{array}{l}66.9(50.0 ; 89.7) \\
64.9(55.3 ; 116.3) \\
59.9(50.7 ; 68.3)\end{array}$ \\
\hline
\end{tabular}

${ }^{\star} P<0.05$ for difference versus NGT, ${ }^{\dagger} P<0.05$ for difference versus GDM2, ${ }^{\ddagger} P<0.01$ for difference between $\mathrm{BMI}$ categories. ${ }^{\S} \mathrm{BMI}<25, n=2$, data not computed. 

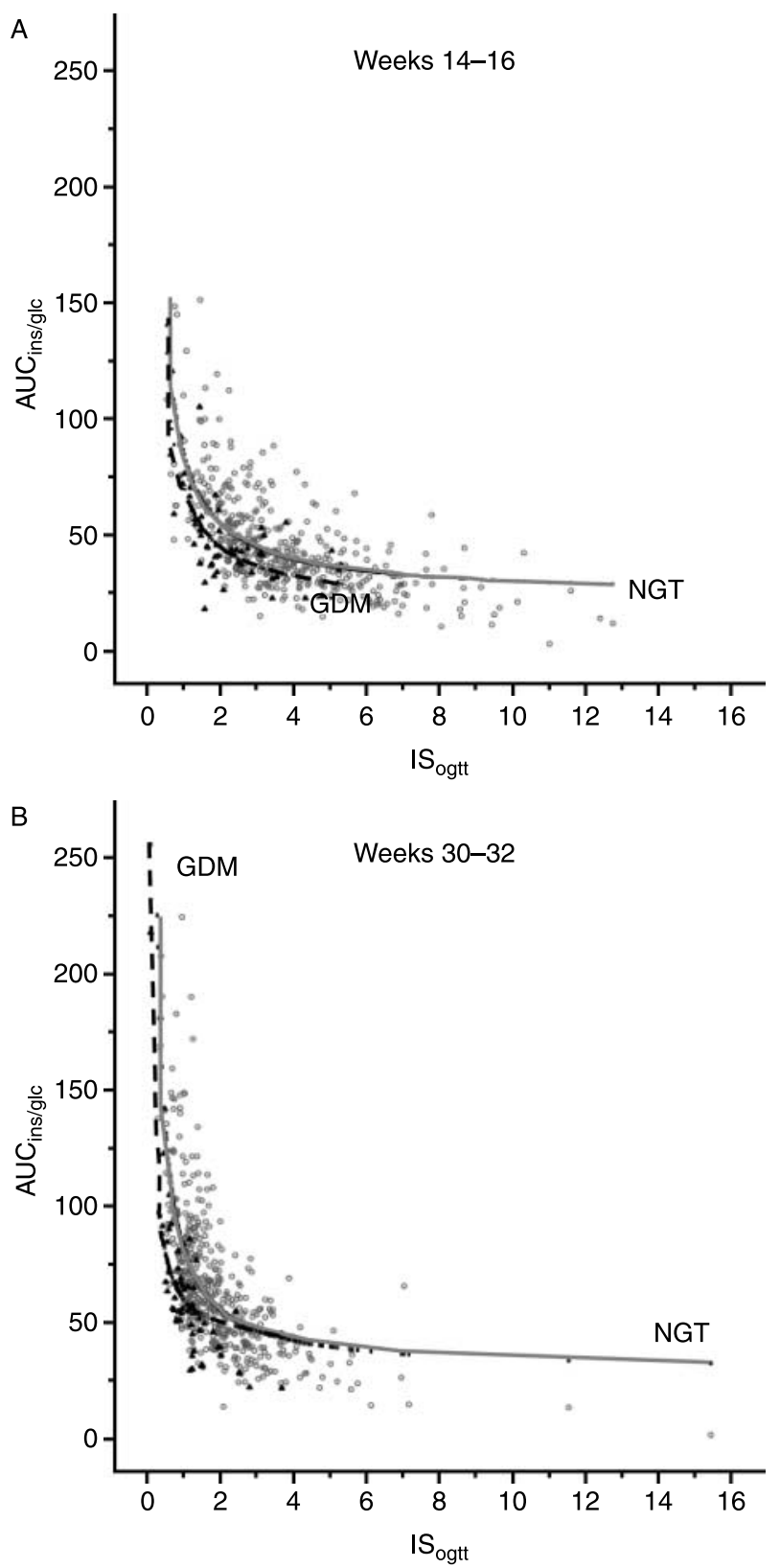

Figure 2 Shifts in $\beta$-cell function $\left(A \cup C_{\text {ins } / g l c}\right)$ and insulin sensitivity $\left(\mathrm{IS}_{\mathrm{ogtt}}\right.$ ) during pregnancy by glucose tolerance group (NGT: $O$; GDM: A ): (A) weeks 14-16; (B) weeks 30-32. The relationships between the indices are given by the hyperbolic curves (GDM: dashed line).

DI changes between glucose tolerance groups At weeks 14-16, DI ${ }_{0}$ in GDM1 and GDM2 subjects was 46 and $30 \%$ lower respectively compared to NGT subjects (both $P<0.0003$, Table 3 ). We found a $23 \%$ difference in $\mathrm{DI}_{\mathrm{O}}$ between GDM1 and GDM2 in early pregnancy $(P<0.02)$, but no significant difference in late pregnancy. At weeks $30-32, \mathrm{DI}_{\circ}$ in NGT was $39 \%$ higher than that in GDM1, and 38\% higher than that in GDM2, both $P<0.0003$.
DI and BMI effects In NGT participants, $\mathrm{DI}_{\mathrm{O}}$ decreased by 18 and $21 \%$ at weeks $14-16$ and 30-32 respectively in overweight individuals $(\mathrm{BMI}>25)$ versus normal weight subjects, both $P<0.0003$ (Table 3). Similarly, when GDM2 participants were categorized by BMI, overweight subjects had $33 \%$ lower $\mathrm{DI}_{\mathrm{o}}$ at both weeks 14-16 and 30-32 (both $P<0.0001$ ).

\section{Discussion}

In this prospective study, $\mathrm{DI}_{o}$ estimates demonstrated definite decreases in $\beta$-cell function in all glucose tolerance categories, among overweight women as well as among normal weight women. $\mathrm{AUC}_{\text {ins/glc }}$ increased during pregnancy, but did not reveal significant changes between glucose tolerance groups. We found the expected decline in dynamic insulin sensitivity during pregnancy, and these changes were accentuated with decreasing glucose tolerance. In overweight subjects, $\beta$-cell function did not differ markedly when categorized by glucose tolerance contrary to the deterioration of insulin sensitivity found in overweight subjects when categorized by glucose tolerance. In our cohort, approximately onefifth of GDM subjects had an early onset of dysglycemia (weeks 14-16) and the rate of GDM was higher than that reported in the Medical Birth Registry (24). These data indicate that in low-risk populations, GDM may be underestimated.

Our cohort is well characterized and had good protocol adherence, consisting of a heterogeneous well-educated urban population of pregnant Caucasian women. The participants had higher pre-gestational weight than those who declined participation (67.2 vs $64.5 \mathrm{~kg}$ ). Furthermore, those who did or did not participate were similar with respect to height, age, parity, smoking habits, marital status, education level, or employment outside home (21).

The OGTT method is considered less physiologic than meal tests due to the large glucose load, and carbohydrate intake previous to overnight fast could also influence the test results. However, the test is simple to perform and is still recommended for diagnostic use in pregnancy (22), in spite of the less-than-perfect reproducibility (25).

Indices of $\beta$-cell function and insulin sensitivity based on peripheral insulin levels are estimates, and could be influenced by altered hepatic extraction. Also, high variability of insulin responses might influence the reliability of computed indices, as is known from the HOMA indices (26). Validation of indices of insulin sensitivity in pregnancy has been done in women with NGT $(n=10)$ and GDM $(n=5)$ using clamp studies and OGTT (15). Correlations between clamp results and $\mathrm{IS}_{\text {ogtt }}$ were in the range of $0.6-0.8$, depending on glucose tolerance and time in pregnancy, and correlations between these dynamic methods performed 
Table $3 \beta$-cell function adjusted for insulin sensitivity (disposition index $\left(\mathrm{DI}_{\mathrm{o}}\right)$ ), total and in subgroups. $\mathrm{DI}_{\mathrm{o}}=\mathrm{AUC}_{\text {ins } / \mathrm{glc}} \times \mathrm{IS}_{\text {ogtt }}$. Data are median (25\%; $75 \%)$.

\begin{tabular}{lcr}
\hline \multicolumn{3}{c}{ Adjusted $\beta$-cell function $\left(\mathrm{DI}_{\mathrm{o}}\right)$} \\
\hline Gestational weeks & $14-16$ & $30-32$ \\
\hline Total & $132(100 ; 171)$ & $95(72 ; 124)$ \\
NGT & $137(107 ; 173)$ & $100(77 ; 128)$ \\
GDM1 & $74(54 ; 78)^{\star}+$ & $61(47 ; 68)^{\star}$ \\
GDM2 & $96(74 ; 119)^{\star}$ & $620(45 ; 72)^{\star}$ \\
BMI $\leq 25$ & $148(118 ; 180)^{\ddagger}$ & $109(85 ; 137)^{\ddagger}$ \\
NGT & - & - \\
GDM1 & $113(97 ; 162)^{\star}, \ddagger$ & $72(64 ; 79)^{\dagger} \neq$ \\
GDM2 & & \\
BMI $>25$ & $122(96 ; 151)$ & $86(69 ; 111)$ \\
NGT & $75(59 ; 80)^{\star}$ & $54(46 ; 67)^{\star}$ \\
GDM1 & $75(64 ; 96)^{\star}$ & $48(39 ; 63)^{\star}$ \\
GDM2 &
\end{tabular}

${ }^{*} P<0.01$ for difference versus NGT or ${ }^{\dagger} P<0.01$ for difference versus GDM2. ${ }^{\ddagger} P<0.01$ for difference between $\mathrm{BMI}$ categories. ${ }^{\S} \mathrm{BMI}<25, n=2$, data not computed.

better than basal indices. We are not aware of any studies with validation of $\beta$-cell function indices during pregnancy.

Former investigations with indices of $\beta$-cell function and insulin sensitivity are mostly from mid-pregnancy and are not prospective. A cross-sectional study of pregnant Japanese women at three points in gestation demonstrated lower basal insulin sensitivity in GDM and overweight NGT women compared to normal weight NGT women (27). Only GDM subjects had significant declines in insulin sensitivity during gestation. HOMA-B levels in normal weight NGT subjects increased during pregnancy; however, in overweight and GDM subjects there was no increase in the last trimester. In our cohort, insulin sensitivity decreased during pregnancy in both NGT and GDM2. In GDM1, we only found a trend possibly due to the lifestyle intervention in this group.

As to our $\beta$-cell function data, $\mathrm{AUC}_{\mathrm{ins} / \mathrm{glc}}$ increased in both normal and overweight NGT subjects, but in GDM subjects, only overweight gravida increased their $\beta$-cell function during gestation. These results, when compared to the Japanese results, may differ due to ethnicity, which is also relevant for the comparison of BMI groups. In subjects with GDM1, where a stronger $\beta$-cell defect is expected, the scarcity of cases in this cohort could influence our ability to detect changes in $\beta$-cell function indices.

Early onset of GDM (weeks 16-20) was found in 40\% of subjects with GDM and normal BMI when tested with $75 \mathrm{~g}$ OGTT (4). In the early-onset group, significant reductions in $\beta$-cell function were found, as well as decreases in insulin sensitivity. Additionally, this group demonstrated a defect in compensation for IR, whereas $\beta$-cell function adjusted for insulin sensitivity in GDM subjects with a late onset did not differ from that in NGT subjects.

Pregnant Caucasian women who were referred for $100 \mathrm{~g}$ OGTT after positive glucose challenge tests (weeks 24-28) had impaired $\beta$-cell function relative to their degree of glucose intolerance based on the Stumvoll phase 1 and the IS $_{\text {ogtt }}$ indices (19). We have calculated the same composite (with Stumvoll phase 1 index and $\left.\mathrm{IS}_{\text {ogtt }}\right)$ from our dataset; results similar to the $\mathrm{AUC}_{\text {ins/glc }}$ composite, for both the cohort and the subgroups, emerged. Correlation analysis of these two composites from our cohort resulted in $r=0.70-0.93$ (data not shown).

The verification of several $\beta$-cell function and insulin sensitivity indices as components of a hyperbolic relationship based on OGTT data, i.e. an oral DI, was recently done in NGT and GDM women post partum (17). In this cohort, only the combination of $\mathrm{IS}_{\text {ogtt }}$ and $\mathrm{AUC}_{\text {ins/glc }}$ fit the strict hyperbolic criteria in both NGT and IGT subjects. We are not aware of similar data in pregnant women, but the above cohort encompasses a broad range of glycemias, i.e. women of childbearing age with NGT, IGT and diabetes, covering the range of glycemias found in our cohort.

The natural course of dysglycemia in our GDM1 subjects may have been obscured by mandatory lifestyle intervention after the diagnosis of GDM. The arrested deterioration in most indices from weeks 14-16 to 30-32 in this group, in comparison with GDM2 subjects, may reflect that lifestyle intervention was effective (28).

The HAPO study recently demonstrated that the risk of adverse pregnancy outcome increases continuously over the whole range of nondiabetic glucose levels (12). Our prospective data outline an impairment of $\beta$-cell function in the preclinical stages of GDM, which is masked by decreasing insulin sensitivity in pregnancy. In overweight women, this impairment is exacerbated, presumptively increasing the risk for adverse pregnancy outcomes and earlier transition to overt diabetes after pregnancy.

\section{Conclusion}

We have found deterioration of $\beta$-cell function adjusted for insulin sensitivity in glucose-tolerant women and more so in glucose-intolerant women in the course of pregnancy. This failure to compensate decreases in insulin sensitivity was accentuated in both early and late pregnancies in overweight women.

\section{Declaration of interest}

The authors declare that there is no conflict of interest that could be perceived as prejudicing the impartiality of the research reported 


\section{Funding}

The study was supported by funds from the Norwegian Resource Centre of Women's Health, Division of Obstetrics and Gynecology, University of Oslo, Rikshospitalet, and by the Faculty of Medicine, Thematic Research Area, University of Oslo, Norway.

\section{Acknowledgements}

The help and advice of the following persons is gratefully acknowledged: the laboratory personnel and nurses at the Department of Endocrinology and the Department of Obstetrics and Gynecology, for their efforts during the trial visits, and Kathrine Frey Frøslie for statistical advice.

\section{References}

1 Catalano PM, Tyzbir ED, Roman NM, Amini SB \& Sims EA. Longitudinal changes in insulin release and insulin resistance in nonobese pregnant women. American Journal of Obstetrics and Gynecology 1991165 1667-1672.

2 Ryan EA \& Enns L. Role of gestational hormones in the induction of insulin resistance. Journal of Clinical Endocrinology and Metabolism 198867 341-347.

3 Langer O, Yogev Y, Xenakis EM \& Brustman L. Overweight and obese in gestational diabetes: the impact on pregnancy outcome. American Journal of Obstetrics and Gynecology 2005192 $1768-1776$.

4 Lapolla A, Dalfra MG, Mello G, Parretti E, Cioni R, Marzari C, Masin M, Ognibene A, Messeri G, Fedele D, Mari A \& Pacini G. Early detection of insulin sensitivity and beta-cell function with simple tests indicates future derangements in late pregnancy. Journal of Clinical Endocrinology and Metabolism 200893 876-880.

5 Bergman RN, Phillips LS \& Cobelli C. Physiologic evaluation of factors controlling glucose tolerance in man: measurement of insulin sensitivity and beta-cell glucose sensitivity from the response to intravenous glucose. Journal of Clinical Investigation 198168 1456-1467.

6 Kahn SE, Prigeon RL, McCulloch DK, Boyko EJ, Bergman RN, Schwartz MW, Neifing JL, Ward WK, Beard JC \& Palmer JP. Quantification of the relationship between insulin sensitivity and beta-cell function in human subjects. Evidence for a hyperbolic function. Diabetes $1993 \mathbf{4 2} 1663-1672$.

7 Droyvold WB, Nilsen TI, Kruger O, Holmen TL, Krokstad S, Midthjell K \& Holmen J. Change in height, weight and body mass index: longitudinal data from the HUNT Study in Norway. International Journal of Obesity 200630 935-939.

8 Kjos SL \& Buchanan TA. Gestational diabetes mellitus. New England Journal of Medicine 1999 341 1749-1756.

9 Buchanan TA. Pancreatic B-cell defects in gestational diabetes: implications for the pathogenesis and prevention of type 2 diabetes. Journal of Clinical Endocrinology and Metabolism 2001 86 989-993.

10 Goldman M, Kitzmiller JL, Abrams B, Cowan RM \& Laros RK Jr. Obstetric complications with GDM. Effects of maternal weight. Diabetes $1991 \mathbf{4 0} 79-82$.

11 Suhonen L \& Teramo K. Hypertension and pre-eclampsia in women with gestational glucose intolerance. Acta Obstetricia et Gynecologica Scandinavica 199372 269-272.

12 Metzger BE, Lowe LP, Dyer AR, Trimble ER, Chaovarindr U, Coustan DR, Hadden DR, McCance DR, Hod M, McIntyre HD,
Oats JJ, Persson B, Rogers MS \& Sacks DA. Hyperglycemia and adverse pregnancy outcomes. New England Journal of Medicine 2008358 1991-2002.

13 DeFronzo RA, Tobin JD \& Andres R. Glucose clamp technique: a method for quantifying insulin secretion and resistance. American Journal of Physiology 1979237 E214-E223.

14 Pacini G \& Mari A. Methods for clinical assessment of insulin sensitivity and beta-cell function. Best Practice $\mathcal{E}$ Research. Clinical Endocrinology and Metabolism 200317 305-322.

15 Kirwan JP, Huston-Presley L, Kalhan SC \& Catalano PM. Clinically useful estimates of insulin sensitivity during pregnancy: validation studies in women with normal glucose tolerance and gestational diabetes mellitus. Diabetes Care 200124 1602-1607.

16 Bergman RN, Ader M, Huecking K \& Van Citters G. Accurate assessment of beta-cell function: the hyperbolic correction. Diabetes 200251 S212-S220.

17 Retnakaran R, Shen S, Hanley AJ, Vuksan V, Hamilton JK \& Zinman B. Hyperbolic relationship between insulin secretion and sensitivity on oral glucose tolerance test. Obesity $2008 \mathbf{1 6}$ 1901-1907.

18 Utzschneider KM, Prigeon RL, Faulenbach MV, Tong J, Carr DB, Boyko EJ, Leonetti DL, McNeely MJ, Fujimoto WY \& Kahn SE. Oral disposition index predicts the development of future diabetes above and beyond fasting and 2-h glucose levels. Diabetes Care 200932 335-341.

19 Retnakaran R, Hanley AJ, Raif N, Hirning CR, Connelly PW, Sermer M, Kahn SE \& Zinman B. Adiponectin and beta cell dysfunction in gestational diabetes: pathophysiological implications. Diabetologia 200548 993-1001.

20 Voldner N, Qvigstad E, Froslie KF, Godang K, Henriksen T \& Bollerslev J. Increased risk of macrosomia among overweight women with high gestational rise in fasting glucose. Journal of Maternal-Fetal \& Neonatal Medicine 20099 1-8.

21 Voldner N, Froslie KF, Bo K, Haakstad L, Hoff C, Godang K, Bollerslev J \& Henriksen T. Modifiable determinants of fetal macrosomia: role of lifestyle-related factors. Acta Obstetricia et Gynecologica Scandinavica 200887 423-429.

22 Alberti KG \& Zimmet PZ. Definition, diagnosis and classification of diabetes mellitus and its complications. Part 1: diagnosis and classification of diabetes mellitus provisional report of a WHO consultation. Diabetic Medicine 199815 539-553.

23 Matsuda M \& DeFronzo RA. Insulin sensitivity indices obtained from oral glucose tolerance testing: comparison with the euglycemic insulin clamp. Diabetes Care 199922 1462-1470.

24 The Norwegian Institute of Public Health. Medical Birth Registry 2006. Available at http://www.fhi.no. Accessed 30-3-2009.

25 Schousboe K, Henriksen JE, Kyvik KO, Sorensen TI \& Hyltoft PP. Reproducibility of S-insulin and B-glucose responses in two identical oral glucose tolerance tests. Scandinavian Journal of Clinical and Laboratory Investigation 200262 623-630.

26 Wallace TM, Levy JC \& Matthews DR. Use and abuse of HOMA modeling. Diabetes Care 200427 1487-1495.

27 Endo S, Maeda K, Suto M, Kaji T, Morine M, Kinoshita T, Yasui T \& Irahara M. Differences in insulin sensitivity in pregnant women with overweight and gestational diabetes mellitus. Gynecological Endocrinology 200622 343-349.

28 Crowther CA, Hiller JE, Moss JR, McPhee AJ, Jeffries WS \& Robinson JS. Effect of treatment of gestational diabetes mellitus on pregnancy outcomes. New England Journal of Medicine 2005352 2477-2486.

Received 15 October 2009

Accepted 19 October 2009 